\title{
Compras Públicas: Estratégia e Instrumento para a Gestão do Desenvolvimento Local
}

Public Procurement: Strategy and Instrument for Management of Local Development Achats Publics: Stratégie et Instruments pour la Gestion du Développement Local Contratación Pública: Estrategia e Instrumento para la Gestión del Desarrollo Local

\author{
Eduardo de Lima Caldas* \\ (eduardocaldas@usp.br) \\ Raquel Sobral Nonato** \\ (kell.sobral@gmail.com)
}

Recebido em 07/11/2012; revisado e aprovado em 23/01/2013; aceito em 16/02/2013

\begin{abstract}
Resumo: Este artigo é resultado de análise e reflexão sobre a importância das compras públicas na gestão do desenvolvimento local. Neste artigo, são apresentados os antecedentes das recentes experiências de desenvolvimento local. Em seguida, é apresentado o atual panorama das compras públicas no Brasil como estratégia para a promoção do desenvolvimento local. Por fim, é apresentado um estudo de caso sobre compras públicas no município de Osasco. Palavras-chaves: Compras públicas. Desenvolvimento local. Políticas públicas.

Abstract: This article is the result of analysis and reflection on the importance of public procurement practices in the management of local development. In this paper, we present the background of recent experiences of local development. Then we present the current scenario of public procurement in Brazil as a strategy for promoting local development. Finally, we present a case study on public procurement in Osasco.

Key words: Procurement. Public policies. Local development.

Résumé: Cet article est le résultat de l'analyse et de réflexion sur l'importance des achats publics dans la gestion du développement local. Dans cet article, nous présentons "l'histoire récente" des expériences de développement local. Ensuite, nous présentons la situation actuel des achats publics au Brésil comme une stratégie visant à promouvoir le développement local. Enfin, nous présentons une étude de cas sur les achats publics à Osasco.

Mots-clés: Achats publiques. Développement local. Politiques publiques.

Resumen: Este artículo es el resultado del análisis y la reflexión sobre la importancia de la contratación pública en la gestión del desarrollo local. En este artículo se presenta la historia reciente de las experiencias de desarrollo local. A continuación se presenta el panorama actual de la contratación pública en Brasil, como una estrategia para promover el desarrollo local. Por último, se presenta un estudio de caso sobre la contratación en Osasco.

Palabras clave: Contratación. De desarrollo local. Políticas públicas.
\end{abstract}

\section{Introdução}

Este trabalho procura trazer uma contribuição no campo de estudos sobre Desenvolvimento Local, observando as compras públicas governamentais como instrumento fundamental para organizar a demanda e favorecer a capilaridade de recursos financeiros no território. Há uma série de experiências de desenvolvimento local, observadas e analisadas a partir do uso de estratégias e instrumentos, dentre os quais, facilitação de acesso ao crédito, qualificação da mão de obra, apoio técnico, dentre outros. No entanto, desde meados dos anos 90, raras foram as experiências de desenvolvimento local que contribuíram com a organização da demanda como instrumento e estratégia para aumen- tar a capilaridade de recursos financeiros no território.

O presente trabalho está organizado em cinco partes, além desta introdução e das conclusões: Nota Metodológica; Antecedentes; Um olhar keynesiano sobre as Compras Públicas; um Estudo de Caso sobre Osasco; Observações Finais.

Na seção sobre "antecedentes" buscarse-á apresentar experiências tanto sobre instrumentos e estratégias de desenvolvimento local identificadas no período, demonstrando uma reorientação das políticas públicas nesse setor. Na seção que trata do "olhar keynesiano sobre as compras públicas" procurar-se-á apresentar as ideias de Keynes relacionadas à redução das importações e ao aumento dos gastos públicos como mecanismos para

\footnotetext{
* Universidade de São Paulo (USP), São Paulo, SP, Brasil.

** Fundação Getulio Vargas (EAESP-FGV), São Paulo, SP, Brasil
} 
aumentar a capilaridade de recursos no território, na mesma seção, é apresentado o arcabouço institucional e jurídico na qual as compras públicas estão inseridas. Em seguida, será apresentado um estudo de caso sobre compras públicas, estruturado como política pública no município de Osasco.

A referida política é denominada "Projeto Educação e Inclusão" e, ao mesmo tempo que oferece formação e qualificação socioprofissional no setor têxtil e de confecção, garante o escoamento do produto gerado no setor por meio da compra pública de "uniformes escolares". Se do lado da produção, garante-se a formação e qualificação pelo lado da oferta, e a compra pública pelo lado da demanda, olhando pela ótica do consumo, observa-se a redução das despesas das famílias que têm filhos matriculados na Rede Municipal de Educação Infantil e Ensino Fundamental, visto que a distribuição dos "uniformes escolares" para a rede municipal de ensino é gratuita. Além desses aspectos, deve-se considerar o reconhecimento público da referida experiência ${ }^{1}$, mais um elemento que justifica o esforço para sua compreensão.

Finalmente, serão apresentadas as observações finais a partir da experiência de Osasco no contexto temático, ou seja, no contexto das experiências de desenvolvimento local e especificamente das experiências de compras públicas vistas no estudo de caso.

\section{Nota Metodológica}

A metodologia desta pesquisa está amparada em um conjunto de instrumentos, dentre os quais uma espécie de "arqueologia" da literatura sobre o tema "compras públicas" articulando-o com uma ideia de desenvolvimento local e um estudo de caso a partir do qual foram realizadas várias "visitas de campo", feitas observações livres, e realizadas entrevistas semiestruturadas.

Dessa forma, tal abordagem foi escolhida por entender que os objetivos da pesquisa não pretendiam mensurar tão somente elementos rigorosamente quantificáveis, mas

\footnotetext{
${ }^{1}$ Em 2008 o projeto ficou em segundo lugar no Prêmio "Boas Práticas do Bolsa Família", organizado pelo Ministério do Desenvolvimento Social e Combate à Fome (MINISTÉRIO DO DESENVOLVIMENTO SOCIAL E COMBATE A FOME, 2011).
}

buscava compreender de que maneira as experiências de uso do poder de compra estão sendo utilizadas no contexto apresentado, a partir da descrição e análise da trama das relações sociais observáveis.

Segundo Yin (2005), o estudo de caso busca "investigar um fenômeno contemporâneo, no contexto da vida real, especialmente quando as fronteiras entre o fenômeno e o contexto não estão perfeitamente delimitadas" (p. 13). Ao discutir a pertinências dos estudos de caso com "experiências únicas", Yin (2005), afirma que essas situações se justificam quando a experiência é ilustrativa. No caso de Osasco, a prática desenvolvida é ilustrativa no que se refere ao mecanismo de compras públicas visando ao desenvolvimento local.

Dentre os recortes possíveis, a pesquisa priorizou a observação das arenas em que a política foi construída e é desenvolvida, e dos atores envolvidos que permearam o processo de tomada de decisão ao longo da implementação da referida prática. As arenas se reportam ao cenário no qual o processo decisório foi realizado (Câmara Municipal e interior do Poder Executivo) a partir da coalizão entre grupos, interesse e, principalmente, poder (LOWI, 1964). Os atores envolvidos, por sua vez, foram considerados como capazes de transformar oportunidades em políticas públicas por meio de seu poder de negociação (LINDBLOM, 2006).

Segundo Roberto Damatta (1974), a atividade do pesquisador é dividida em três fases. A primeira compreende a fase "teóricointelectual", na qual o pesquisador deve se esforçar para realizar a aproximação entre objeto de estudo e suas impressões, de modo a familiarizar-se com o exótico e distanciar-se do que lhe é comum. A segunda compreende o "período prático", cujo objetivo é realizar uma imersão na experiência observada de modo a destacar os aspectos orgânicos e identificar os problemas "banalmente concretos". A última fase é denominada "pessoal ou existencial", na qual as lições e o aprendizado sobre o caso estudado são depreendidos contribuindo para o surgimento de novas percepções do pesquisador.

Sobre isso, Peter Spink ressalta que observar o campo na perspectiva dos "microlugares" não é se distanciar completamente do objeto de estudo, mas tornar-se parte do 
cotidiano, partindo da premissa que o "cotidiano é tudo que temos"

a noção de microlugares é um duplo desafio: primeiro de aprender a prestar atenção a nossa própria cotidianidade, reconhecendo que é nela que são produzidos e negociados os sentidos e, segundo, de aprender a fazer isso como parte ordinária do próprio cotidiano, não como um pesquisador participante e muito menos como um observador distante, mas simplesmente como parte. Se o primeiro já é difícil o segundo desafio requer a disposição de repensar muito daquilo que é presumido como central à "boa pesquisa científica". (SPINK, 2008, p. 71).

A escolha do município de Osasco se deu, primordialmente, pela motivação em investigar e compreender a redefinição dos instrumentos estatais advindos de novos elementos identificáveis no âmbito das políticas públicas de desenvolvimento local por meio da inclusão social e geração de renda e ocupação na região ${ }^{2}$.

Uma vez delimitado o escopo da pesquisa, foi realizada a revisão bibliográfica contemplando a ideia de "compras públicas como indutor do desenvolvimento local".

Para levar a cabo a pesquisa, lançou-se mão de um conjunto de instrumentos, focados na revisão da literatura, consultas em fontes primárias de informação (relatórios internos, editais e processos administrativos), observação livre, conversas informais, registro fotográfico, visitas de campo, além da realização de entrevistas com os atores envolvidos, além de impressões e inquietações registradas no diário de campo.

Os roteiros de entrevistas aplicados na pesquisa em questão foram inspirados no Programa Gestão Pública e Cidadania (PGPC), da

\footnotetext{
${ }^{2}$ Em princípio foi pensado desenvolver a pesquisa em torno do programa "Osasco Solidária", criado em 2005, que abrange o projeto escolhido na presente pesquisa. Assim, foi realizada uma primeira visita às principais atividades executadas pelo programa: Incubadora Pública de Empreendimentos Solidários, Centro Público, Inclusão de produtores locais na reurbanização de favelas no bairro Morro do Socó e o "Projeto Educação e Inclusão". Ao perceber a amplitude das ações, entendeu-se que seria mais adequado estudar o "Projeto Educação e Inclusão", uma vez que a experiência trazia elementos interessantes, tais como a identificação da rede de apoio na gestão do projeto e dos mecanismos de compras públicas utilizados em sua implementação.
}

Fundação Getúlio Vargas (FGV), iniciativa reconhecida como de grande contribuição para a sistematização e disseminação de práticas de gestão pública em contexto subnacional. As entrevistas se concentraram fundamentalmente no segundo semestre de 2011, ou seja, cinco anos após a implementação da referida política pública e um ano antes das eleições municipais $^{3}$.

\section{Antecedentes}

A valorização do local enquanto espaço de poder capaz de articular conjuntos diferentes de ação e de atores está no centro das transformações que envolvem a descentralização, a desburocratização e a participação, bem como as chamadas novas "tecnologias urbanas" (DOWBOR, 2009). Trata-se da superação da perspectiva de ação encontrada no período anterior a 1988, vista tão somente como iniciativa isolada, não fazendo parte da estratégia de desenvolvimento do país.

Vaz e Caldas (2006) organizam as experiências de desenvolvimento local recentes em 3 fases: "antecedentes", "grande encruzilhada" e "o despertar tardio". A primeira fase compreende o período de 1976 a 1988,

\footnotetext{
${ }^{3}$ Sobre os roteiros de entrevista, deve-se considerar que foi organizado um roteiro inicial, contendo as primeiras informações sobre o Projeto Educação e Inclusão e encaminhado à Secretaria do Desenvolvimento Trabalho e Inclusão (SDTI), órgão público responsável pela gestão do projeto. O Segundo passo foi a elaboração de um roteiro de entrevista semiestruturado direcionado aos responsáveis da referida prática: Sandra Faé Praxedes Secretária do Secretária do Desenvolvimento, Trabalho e Inclusão; Paulo Marcelino - Representante da Secretaria da Educação no Comitê Gestor da execução do projeto; Celso Pedro - Coordenador da Associação Eremim; e Gerson Guimarães - Coordenador de projetos do Instituto de Tecnologia Social (ITS BRASIL). Com essas informações foi elaborado um segundo roteiro de entrevista semiestruturada aplicado aos representantes dos grupos de interesse envolvidos ao longo do processo. Finalmente, entendendo a especificidade do grupo ligado ao setor da educação principalmente por estarem ligados ao recebimento do produto final (os uniformes escolares), foi elaborado um terceiro roteiro de entrevista e aplicados nas escolas EMEF Prof. João Larizzati , CEMEI Alice Manholer Piteri e EMEF Maestro Domingo Blasco, as duas primeiras localizadas nos bairros $\mathrm{Km} 18$ e a terceira no bairro Novo Osasco. As perguntas foram dirigidas aos pais de alunos, professores e diretores das escolas a fim de destacar os caminhos pelos quais os uniformes escolares passam até chegar ao seu destino final: os alunos
} 
denominada "antecedentes". Essa fase identifica as ações do período como opositora ao Regime Militar e como primeiros ensaios de governos democráticos, nesse cenário, o fortalecimento das instâncias locais representava a tentativa de consolidar espaços de resistência para a redemocratização em busca de maior autonomia para os governos subnacionais. Entre as ações identificadas no período estão os municípios de Lajes, SC e Boa Esperança, ES (MARTINS et al., 2009).

Conforme observam Kugelmas e Sola (1999, p. 67), "no momento da promulgação da Constituição de 1988, a reação à centralização fiscal do regime autoritário atingiu seu ponto culminante; o padrão de organização federativa que então emerge é tido como um dos mais descentralizados entre os países em desenvolvimento", assim, a descentralização vem consonante aos anseios de democratização do processo decisório e controle social. Para Farah, a descentralização política e administrativa surge em um cenário de redefinição no plano econômico. Assim, de um lado aparece a necessidade de redistribuir o poder entre os entes da Federação no plano político e econômico e, em paralelo a isso, surge um forte discurso neoliberal que propagava um Estado mínimo.

O período de 1989-1993 é denominado como a "grande encruzilhada" (VAZ; CALDAS , 2006), porque a redemocratização brasileira e a promulgação da Constituição Federal de 1988 indicaram a mudança do paradigma da ação estatal no nível local, ampliando as competências dos municípios, aumentando suas capacidades em tributar, incrementando recursos por meio das transferências do Fundo de Participação dos Municípios (FPM) e da Cota Parte do Imposto sobre o Comércio de Mercadorias e serviços (ICMS), mas, pari passu a isso, as demandas por políticas públicas sociais reprimidas pelo período de Ditadura Militar incidiram sobre os municípios que, por sua vez, já não apresentavam alternativas ao Regime, mas tão somente faziam a gestão da crise existente; finalmente, a terceira fase denominada "o despertar tardio" se relaciona à centralização do governo local a partir de 1993, cujas responsabilidades foram mantidas e iniciativas de desenvolvimento local começam a ganhar força (VAZ; CALDAS , 2006).

A terceira fase denominada "o despertar tardio" se relaciona à centralização do governo local a partir de 1993, cujas responsabilidades são mantidas e iniciativas de desenvolvimento local começam a ganhar força (VAZ; CALDAS , 2006).

Nesse contexto, surgem iniciativas de apoio a arranjos produtivos locais, por meio do uso do poder de compra do Estado, de políticas públicas de microcrédito, de cooperação entre os municípios por meio dos consórcios intermunicipais e da disseminação do Orçamento Participativo entre as prefeituras municipais, indicando uma reorientação das políticas públicas nesse setor.

\section{Um olhar keynesiano sobre compras públicas}

As compras públicas guardam forte relação com a ação do Estado em ativar dispositivos para dinamizar a economia local, uma vez que movimentam recursos estimados em $10 \%$ do PIB brasileiro (CATTANI; FERRARINI, 2010). Trata-se de um mercado de mais $\mathrm{R} \$ 350$ bilhões/ano, do qual apenas $20 \%$ dos pequenos negócios participam, mesmo considerando que esse tipo de negócio representa $99,2 \%$ das empresas formais brasileiras (MORAIS, 2005).

No âmbito internacional, a inserção das compras públicas nos debates sobre a integração de blocos econômicos para a expansão das transações comerciais entre os países, tais como a Organização Mundial do Comércio (OMC), a União Europeia (UE), NAFTA, Estados Unidos da América (EUA), estão cada vez mais presentes, evidenciando seu papel estratégico nas discussões sobre a ação estatal e o desenvolvimento (MOREIRA; MORAIS, 2003).

A presente seção parte da perspectiva teórica de que a tradição econômica de intervenção do Estado está intimamente ligada às experiências que utilizam o exercício do poder de compra. Avançando para o campo empírico, são apresentadas suas recentes interfaces com o plano jurídico brasileiro, de modo a destacar como estão sendo desdobradas, limitadas e articuladas as políticas públicas para impulsionar a referida ação estatal.

Lima e Pitaguari (2005), a partir do enfoque keynesiano, propõem que a dinamização da demanda efetiva no nível local está intrinsecamente ligada à base produtiva 
de exportação e ao investimento do setor público em setores estratégicos por meio do gasto público.

Deve-se ressaltar que as alterações na demanda efetiva, advinda da expansão das atividades de exportação ou da despesa pública, têm três efeitos sobre a renda da economia local: um efeito direto associado à remuneração das famílias, que dependem do setor exportador; um efeito indireto, que vai estimular a produção dos setores não exportadores; um efeito induzido pelo acréscimo de renda causado pela expansão do emprego nos setores exportadores e não exportadores. (LIMA; PITAGUARI, 2005).

Tal perspectiva remonta estudos de meados dos anos 80 no Canadá e nos Estados Unidos da América (EUA) e traz em si elementos passíveis de observação sobre a atuação estatal na dinâmica local. O estudo de Davis (1987) evoca importantes contribuições acerca do tema, por meio de uma abordagem teórica e empírica.

O autor traz experiências bem sucedidas no estado de Oregon nos EUA e em províncias canadenses no que se refere à substituição de importações, o que ele denomina "Buy-local". O autor conclui que tal prática representa um elemento de força no apoio à economia local, gerando um efeito multiplicador no processo que é descrito a seguir:

A dollar decrease in import purchases will indeed have the same impact on the local economy as a dollar increase in export sales, all other things equal. But a decrease in imports is only half of the process of import substitution. The other half of the process is an increase in local production. A dollar of import substitution (the replacement of a dollar of imports by a dollar of local production) will thus have a greater impact on the local economy than will a dollar increase in exports. While it is correct, as Hoover states, that in both cases local production has increased by one dollar, in the case of import substitution, in contrast with export expansion, the local multiplier has been slightly increased. (DAVIS, 1987, p. 03) ${ }^{4}$.

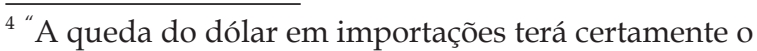
mesmo impacto sobre a economia local quanto um aumento do dólar em vendas para exportação. Porémuma diminuição das importações é apenas metade do processo de substituição de importações. A outra metade do processo é um aumento em produção de dólar. Um dólar de substituição de importações (a
}

Sobre os resultados da aplicação do Buy-Local, Davis ressalta algumas vantagens em utilizar bens e serviços produzidos no âmbito local, entre eles a eliminação de despesas intermediárias como transporte e câmbio, além do aumento da diversidade da economia local representando um ganho adicional resultante do processo (1987). Ainda sobre isso, Davis elucida a conexão causal de programas de fomento a este processo e a criação de emprego e, consequentemente, dos impactos sentidos na economia local, alcançando assim, o fortalecimento e a expansão da produção local.

Jane Jacobs (1974) também tece importantes considerações sobre o efeito multiplicador gerado ao investir na economia local. Para a autora, as cidades têm o poder de alavancar o desenvolvimento econômico à medida que o mercado local é fortalecido. $\mathrm{O}$ the export-multiplier efect aumenta os níveis de emprego local gerando um círculo virtuoso onde a produção no mercado local induz o desenvolvimento de novos bens e serviços para o consumo interno e externo.

Dessa maneira, traduzindo tal estratégia em mecanismos utilizados pelo Estado no processo de compras públicas, podem ser apontadas políticas públicas nesse setor. Entre elas, podem ser destacadas as de fomento à tecnologia nacional e aumento de competitividade no nível internacional; a flexibilização e desburocratização na formalização de micro e pequenas empresas, principalmente por meio alteração na legislação; o apoio instrumental fomentando a criação de empreendimentos coletivos, realizado por meio de políticas públicas de incentivo; a oferta de crédito, articulando com outros equipamentos públicos tais como agências de fomento, de modo a diminuir os riscos envolvidos, entre outros.

A presença de órgãos que atuam sistematicamente na capacitação de servidores e fornecedores sobre compras públicas também é um ponto relevante, destacando-se nesse

substituição de um dólar das importações por um dólar de produção local) terá assim um maior impacto na economia local do que será um aumento do dólar nas exportações. Embora seja correto, como Hoover afirma que, em ambos os casos, a produção local tem aumentado por um dólar, no caso de substituição de importações, em contraste com a expansão das exportações, o efeito multiplicador local foi ligeiramente aumentado" (Tradução Livre). 
aspecto o Serviço Brasileiro de Apoio às Micro e Pequenas Empresas (SEBRAE), que por meio de realização de eventos e publicação de cartilhas, promove importante contribuição sobre a temática.

No plano jurídico, entre as normas que atualmente regem o processo de aquisição governamental estão a Lei de Responsabilidade Fiscal e a Lei de Licitações e Contratos $8.666 / 93$, criadas com o intuito de promover maior transparência e controle sobre os gastos públicos. Alterada em 2010 (Lei 12.349/10), o art. $3^{\circ}$ da Lei 8.666/93, reza que a função da licitação não é tão somente obter a proposta mais vantajosa, mas promover o desenvolvimento inclusivo, de forma a direcionar a demanda do Estado para o desenvolvimento local.

A Lei complementar n. 123, 14 de dezembro de 2006, que institui o Estatuto Nacional da Microempresa e da Empresa de Pequeno Porte, representa outro marco legal importante sobre essa temática, isso porque, tal lei dispõe, entre outras coisas, sobre a preferência de organizações associativista e inclusivas no processo de licitação.

Com efeito, o enrijecimento da normativa apresentada é apontado como uma grande barreira para institucionalizar novas práticas no setor, fato que acaba favorecendo muitas vezes empresas já consolidadas no mercado, não beneficiando modelos alternativos de incremento produtivo. Atualmente, as compras públicas permeiam duas questões principais. A primeira se relaciona à utilização de insumos que promovam o desenvolvimento sustentável, de maneira a favorecer produtores que reduzam as externalidades negativas causadas pela produção de um determinado produto, substituindo materiais degradantes por materiais sustentáveis, são as chamadas compras verdes ou sustentáveis (BIDERMAN et al., 2008).

A segunda, por sua vez, compreende o ato do Estado de investir em setores socialmente estratégicos para a inclusão e a otimização da produção (MOREIRA; MORAIS, 2003) por intermédio de políticas públicas de incremento à economia local, desenvolvendo a competitividade industrial e tecnológica, além de fomentar Arranjos Produtivos Locais (APLs) e relações comerciais nos moldes da Economia Solidária. Compreendendo a especificidade do presente estudo de caso, será priorizada a questão das compras públicas em sua relação com o incremento produtivo local.

Dessa forma, o exercício do poder de compra do Estado ganha maior visibilidade nas questões que cercam o desenvolvimento local à medida que as mudanças contemporâneas fortaleceram uma retomada da ação estatal intervencionista, fato que viabilizou as transformações no contexto estudado.

Apesar dos avanços normativos alcançados, ainda é percebido um "malabarismo jurídico" para institucionalizar novas práticas no setor de compras públicas, principalmente no que diz respeito à formalização de empreendimentos coletivos e da formação de cooperativas que sejam reconhecidas como capazes de ofertar bens e serviços para o poder público.

\section{Um estudo de caso sobre Osasco}

O "Projeto Educação e Inclusão", também conhecido como Oficina Escola ${ }^{5}$, foi criado pela Prefeitura Municipal de Osasco em 2006 e, por meio da integração de um conjunto de políticas públicas, tem os objetivos de promover a qualificação socioprofissional no setor têxtil e confecção de pessoas com baixa renda, e diminuir a despesa das famílias com filhos matriculados na rede municipal do ensino por meio da distribuição gratuita de uniformes escolar ${ }^{6}$.

\footnotetext{
${ }^{5}$ Na realização das entrevistas, muitas vezes, o projeto foi chamado tanto por "Educação e Inclusão" como "Oficina Escola". Para a organização semântica da pesquisa, será compreendido "Educação e Inclusão" o projeto em sua concepção macro considerando assim, a formação profissional e a distribuição dos uniforme como processos interados. Já o termo "Oficina Escola" será utilizado para se referir ao espaço laboral (localizado no bairro Rochdalle/Osasco), onde as beneficiárias do programa exercem as atividades de confecção e costura.

${ }^{6} \mathrm{O}$ município de Osasco está localizado na Região Metropolitana de São Paulo e possui 667.000 habitantes distribuídos em $64 \mathrm{~km}^{2}$ (IBGE, 2010). Conhecido por abrigar historicamente grandes indústrias paulistas, tais como a Companhia Brasileira de Material Ferroviário (COBRASMA), Ford Motor do Brasil S/A (setor automobilístico) e S/A White Martins (setor químico). O município assistiu o êxodo de várias delas, principalmente nas últimas duas décadas, entre elas estavam a ETERNIT, indústria relacionada a materiais de construção, e a empresa SANTISTA, ligada ao setor têxtil e confecção. Com isso, o perfil do município foi alterado, dando lugar à um forte polo comercial, principalmente no setor varejista e atacadista.
} 
Cumprindo o segundo mandato consecutivo, o prefeito Emídio Pereira de Souza (2005-2012), do Partido dos Trabalhadores (PT), rompeu com o período de 22 anos de controle do Partido Trabalhista Brasileiro (PTB) (mandatos de Francisco Rossi, Celso Giglio e Sillas Bortolosso respectivamente) e Partido da Social Democracia Brasileira (PSDB) (Celso Giglio).

Diante esse cenário, em 2005 a Prefeitura Municipal de Osasco apresentou a estratégia de inclusão social para o município. No topo das ações desenvolvidas esteve a criação da Secretaria do Desenvolvimento, Trabalho e Inclusão (SDTI), que atua na municipalização das políticas de emprego e inclusão em Osasco, antes responsabilidade majoritária do governo estadual.

Para compor a equipe técnica da Secretaria, alguns atores com expertise no assunto foram contratados. Muitos deles já haviam desempenhado atividades na Prefeitura de São Paulo no período de 2001 a 2005 (Gestão Marta Suplicy - PT/SP). Sobretudo os técnicos do programa Oportunidade Solidária ${ }^{7}$

\footnotetext{
Atualmente, estão instaladas no município as sedes do Centro das Indústrias do Estado de São Paulo (CIESP), da Federação das Associações Comerciais (FACESP), do SEBRAE, Junta Comercial e sindicatos, além de unidades do SENAI e SENAC. Contudo, a oferta de empregos formais, bem como a qualificação da mão de obra, não acompanhou a real necessidade inerente ao desenvolvimento local e regional. Com o PIB aproximado de 30 bilhões de reais (IBGE, 2010), a distribuição de empregos formais em Osasco está concentrada no setor de serviços, cuja participação é de $52,2 \%$, seguido pelos setores de comércio $(24,7 \%)$ e indústria $(19,7 \%)$ (DIEESE, 2009). Tais dados permitem dizer que Osasco tem grande parcela de sua população em situação de vulnerabilidade social. De acordo com o Cadastro Único (CadÚnico) do Ministério do Desenvolvimento Social e Combate à fome (MDS), 10.790 famílias do município são consideradas extremamente pobres e vivendo com a renda per capita abaixo de R\$70,00 estão inscritas no programa Bolsa Família.

${ }^{7}$ O programa Oportunidade Solidária foi um dos primeiros programas ditos de Economia Solidária no país. Implementado em 2001, o programa previu a criação da Secretaria do Trabalho, Desenvolvimento e Solidariedade para o desempenho das ações, coordenadas por Márcio Pochmann. Importante ressaltar que o desenho e a metodologia aplicada nas atividades desenvolvidas pela SDTI em Osasco é semelhante em grande medida ao caso paulistano. Para mais informações sobre o programa Oportunidade Solidária ver (GOMES; ALVES, 2005) e SILVA (2010).
}

foram integrados ao corpo de servidores, o que permitiu que o conhecimento acumulado fosse incorporado na nova estratégia adotada pelo poder municipal.

Como foi dito anteriormente, o "Projeto Educação e Inclusão" tem por objetivo promover a qualificação social e profissional de trabalhadores em situação de desemprego e vulnerabilidade social. Concomitante a esse objetivo, está a distribuição de uniformes escolares a todos os alunos da rede pública municipal. Também consta como objetivo fomentar a criação e a consolidação de Arranjos Produtivos Locais (APLs) no setor têxtilconfecção, contribuindo para as atividades de Economia Solidária desenvolvidas na região.

No entanto, para alcançar seus objetivos, a implementação do referido projeto demanda a formação de uma rede de governança, composta por um conjunto de atores dentre os quais a SDTI, a Secretaria da Educação (SE), a Associação Eremim (OSCIP EREMIM) e o Instituto de Tecnologia Social (ITS BRASIL).

Concebido como política pública matricial, o projeto prevê a capacitação socioprofissional dos beneficiários e o auxílio técnico na formalização de microempresas e cooperativas. Para garantir e reafirmar a matricialidade como princípio organizacional, o projeto se articula com os programas redistributivos, o Osasco Solidária e Osasco Inclui, sediados na SDTI. Além disso, o projeto se articula com a Secretaria da Educação, a qual tem a responsabilidade de organizar a oferta pelo produto e disponibilizar recursos para a gestão orçamentária do projeto, representando um gasto de 7,6 milhões/ano.

A gestão do "Projeto Educação e Inclusão" é compartilhada e envolve órgãos públicos e entidades da sociedade civil. Em vista do Termo de Parceria n. 213/2009, participam da coordenação do projeto a Secretaria da Educação, a Secretaria do Desenvolvimento, Trabalho e Inclusão e a Secretaria de Assuntos Jurídicos e a Associação Eremim.

Ainda no âmbito do Termo de Parceria, é prevista a criação de um Comitê Gestor, reunido mensalmente, com a função de monitorar e avaliar a execução do projeto. $\mathrm{O}$ Comitê é composto por 2 (dois) representantes da Secretaria da Educação, 2 (dois) representantes da SDTI, 2 (dois) representantes 
da Associação Eremim, 1 (um) membro indicado pelo Conselho Municipal de Educação e 1 (um) membro indicado pela Comissão Municipal do Emprego.

O Estado pode optar por ter maior participação e, por conseguinte, maior controle sobre toda a cadeia de suprimentos no processo de compras públicas. Osasco possui um conjunto articulado de instrumentos que possibilita que o poder público esteja presente tanto no apoio instrumental das beneficiárias como na aquisição de insumos e, principalmente, do produto final demandado pelos alunos. Tal articulação permitiu que Osasco obtivesse um desenho metodológico que favorecesse setores estratégicos da economia local (setor têxtil e confecção).

Desdobrando as atribuições de cada órgão na execução do projeto, a Secretaria da Educação faz o levantamento da demanda e promove a discussão sobre os modelos de uniforme com professores e pais de alunos. Além da determinação sobre a especificidade dos uniformes, a Secretaria da Educação também é responsável pela maior parcela dos recursos dependidos a esse projeto e, em consequência disso, possui voz ativa nas reuniões do Comitê Gestor.

A Secretaria da Educação exerce forte pressão sobre a Oficina Escola e as Cooperativas Setoriais envolvidas no projeto, a fim de que os uniformes sejam confeccionados no prazo estipulado e tenham a qualidade pré-estabelecida. Nesse sentido, o órgão representa um importante "cliente" do projeto acompanhando o processo logístico da confeç̧ão do produto final até a distribuição nas unidades educacionais.

Por ser a mentora do desenho metodológico do projeto, a Secretaria do Desenvolvimento, Trabalho e Inclusão é grande incentivadora das atividades, por meio de acompanhamento em todas as etapas do projeto, desde a formação socioprofissional até o apoio à formalização de Arranjos Produtivos Locais capazes de produzirem bens e serviços para Osasco e região.

As secretarias de Governo e de Assuntos Jurídicos, junto com o Gabinete do Prefeito formam uma triangulação jurídica e são responsáveis pela gestão do convênio e do Termo de Parceria, o qual é renovado a cada dois anos, além das disposições quanto à liberação dos recursos. Nesse sentido, são responsáveis pelos visíveis "malabarismos jurídicos" para justificar a prorrogação do termo e para garantir a continuidade do projeto e no a poio à formalização dos novos mercados que surgiram após a implementação do projeto.

Entre as entidades da sociedade civil está o ITS BRASIL. O ITS é uma Organização da Sociedade Civil de Interesse Público (OSCIP). Embora não tenha envolvimento formal e direto na execução do "Projeto Educação e Inclusão", a organização contribuiu com o seu know-how no delineamento dos projetos executados em Osasco, bem como apoio técnico na realização de atividades de incubação de empreendimentos.

A Associação EREMIM é uma entidade sem fins lucrativos, caracterizada como OSCIP desde o ano de 2003. Ligada ao setor metalúrgico do município, atualmente, ela está envolvida em projetos que atendem crianças e adolescentes no bairro Rochdale, no campo da cultura, esportes e em atividades de promoção de trabalho e renda. Seu papel está relacionado à execução das da Oficina Escola em todas as frentes de atuação: aprendizagem prática; qualificação profissional; formação cidadã; logística e distribuição.

O início do processo que culminou no projeto se deu em 2005, com a estratégia municipal de distribuir os uniformes escolares de forma gratuita, como igualmente acontecia na cidade de São Paulo desde 2002. Porém, diferentemente da capital paulista, Osasco decidiu que o uniforme seria o produto final de um projeto de qualificação profissional desenvolvido pelo próprio município.

Então, foi delineada a estrutura metodológica e definido o público-alvo que seria atendido no "Projeto Educação e Inclusão". Para alcançar os objetivos do projeto, principalmente no que tange à produção própria dos uniformes e à geração de ocupação e renda foi estruturada uma rede de mecanismos utilizados na execução do projeto, principalmente no que se refere ao processo de compras públicas.

Dessa forma, o primeiro passo foi a consolidação de um arcabouço jurídico materializado na Lei 3981/05, que criou o Programa Operação Trabalho (POT) e previu a existência de uma entidade parceira capaz de executar o projeto no setor têxtil e confecção, 
não caracterizando a concorrência desleal na produção dos uniformes.

Art. 1o Fica instituído o Programa Operação Trabalho - POT, com o objetivo de conceder atenção especial ao trabalhador desempregado, preferencialmente com idade entre 25 (vinte e cinco) e 39 (trinta e nove) anos, residente no Município de Osasco e pertencente a família de baixa renda, visando estimulá-lo à busca de ocupação, bem como ampliar suas oportunidades de reinserção no mercado de trabalho.

Art. 2o O Programa Operação Trabalho POT consistirá:

I - no exercício de atividades, realizadas e ministradas pelos órgãos municipais ou por entidades conveniadas ou parceiras;

II - no desenvolvimento de atividades de capacitação ocupacional e de cidadania, implementadas pelos órgãos municipais ou por entidades conveniadas ou parceiras; III - em ações de incentivo e orientação ao beneficiário, desenvolvidas pela SDTI ou por entidades conveniadas ou parceiras, sobre seu comportamento na busca por alternativas de geração de trabalho e renda; IV - na concessão de auxílio pecuniário, correspondente a no máximo um e meio salário mínimo nacional vigente.

Com a alteração normativa, o próximo passo foi escolher o parceiro executor. Nesse momento, foi necessário criar um Edital Público para recrutar aquele que teria a responsabilidade de organizar a produção de uniformes, atendendo a demanda de, em média, 400.000 peças/ano.

No momento de implantar fisicamente a Oficina, foram definidos os detalhes de infraestrutura e de aquisição de materiais por meio de licitação pública. Nessa fase, foi necessário o auxilio de funcionários da prefeitura (do setor de compras públicas) para determinar o procedimento de aquisição e regularização dos contratos referentes à contratação de serviços para setores específicos, tais como o corte de tecidos dos uniformes.

O Termo de Parceria, instrumento jurídico que formaliza a atribuição de responsabilidade de cada ente na execução do projeto, estabelece metas, indicadores, resultados e mecanismos de desembolso para realizá-lo. Renovado a cada dois anos, o Termo de Parceria é amparado por legislação federal (Lei 9.790/199), e estadual (Decreto n. 48.766, de 30/06/2004) e determina que o período má- ximo de vigência não deve ultrapassar 5 anos. Esse fato incidiu em pontos críticos ao projeto, haja vista os riscos envolvidos no que se refere à continuidade das atividades desenvolvidas pela Oficina Escola. Até porque, trocar de entidade executora significa, em grande medida, perder a memória do processo, o que traria inúmeras dificuldades de incorporação dos procedimentos por parte de uma nova parceria. Outro elemento a cerca do Termo de Parceria que representa um obstáculo à execução do projeto são os inúmeros questionamentos do Tribunal de Contas do Estado quanto à origem do gasto orçamentário bem como os procedimentos de aquisição de bens e serviços. Atualmente, é necessário que a Prefeitura envie relatórios periódicos contendo todos os atos relativos à contratação de serviços e recursos utilizados.

A Incubadora Pública de Empreendimentos Populares e Solidários (IPEPS) representou outro instrumento para a consolidação da experiência em questão, uma vez que viabilizou a criação da Oficina Setorial no setor têxtil e confecção denominada Incluindo Ponto a Ponto, cuja função é disponibilizar um espaço que propicie as atividades de planejamento, gestão (contábil, tributária, financeira, fiscal e de recursos humanos), produção e comercialização dos empreendimentos individuais e coletivos na fase de incubação, funções previstas no decreto n. 9.823, assinado em 04 de outubro de 2007.

Tal ação da IPEPS resultou na criação da Cooperativa de Costura Osasco que, desde 2010, complementa a produção de uniformes escolares realizada pela Oficina Escola com 53.00 peças/ano. De acordo com o depoimento de Marize Alves Prazeres, presidente da Cooperativa desde a formalização, a viabilização da criação da cooperativa só foi possível pelo acompanhamento técnico do instrumento em questão. Para estabelecer a relação contratual dos novos participantes, foi necessário desenhar o Chamamento Público n. 01/2010, no qual foram convocados empreendimentos econômicos já existentes e em processo de consolidação e inseri-los no mercado de forma autônoma, a fim de promover a integração destes com a economia local.

Ainda no bojo do apoio organizativo dos novos empreendimentos, está a articulação de linhas de crédito no Banco do Povo. Trata-se 
de um programa de microcrédito do governo estadual, sob administração da Secretaria de Emprego e Relações do Trabalho (SERT), em parceria com as prefeituras municipais, destinados às micro e pequenas empresas, cooperativas, ou empreendedores individuais que desempenham atividade produtiva no município, concedendo empréstimo até $\mathrm{R} \$ 5.000,00$ à pessoa jurídica e $\mathrm{R} \$ 3.000,00$ à pessoa física. Entre as exigências para acessar as linhas de crédito da instituição, estão a não observância de pendências cadastrais no SCPC, SERASA e CADIN Estadual ${ }^{8}$ e ter faturamento bruto menor a R\$ 240 mil no último ano.

O Banco do Povo foi acionado na maioria dos casos em que a beneficiária optou pela Economia Solidária. De acordo com o depoimento de Maria Albertina, ex-beneficiária do projeto, a aquisição das três máquinas profissionais de costura só foi possível devido à disponibilização do microcrédito. Mais recentemente, a implementação do Fundo Municipal de Desenvolvimento e Inclusão Produtiva (FUMDIP), criado pela Lei 4.421, de 31 de maio de 2010, representou um avanço para a consolidação da referida prática no nível local, visando "fomentar a criação, consolidação e a expansão de micro e pequenos empreendimentos, organizações econômicas de caráter coletivo e solidário, iniciativas individuais ou associadas de geração de trabalho e renda, formais ou em fase de formalização, mediante a concessão de empréstimos e de subvenções econômicas".

Uma dimensão das dificuldades observadas no "Projeto Educação e Inclusão" se relaciona com a posição dos atores envolvidos, sobretudo os gestores públicos. Isso porque a viabilidade econômica é posta em prova a todo o momento. Na visão de alguns entrevistados, existe um custo elevado para arcar com toda a infraestrutura e garantir que os uniformes sejam entregues nas condições préestabelecidas. Essa posição se alinha à crítica sobre o exercício de compras públicas em re-

\footnotetext{
${ }^{8}$ SPC, SERASA e CADIN Estadual são respectivamente: Serviço de Proteção ao Crédito (SPC); empresa privada que presta serviço de cadastrar pessoas com débitos não quitados em qualquer instituição financeira ou comercial; (SERASA); Cadastro Informativo dos Créditos Não Quitados de Órgãos e Entidades Estaduais em São Paulo. O CADIN foi instituído por Lei, em 2008 (Lei 12.799, de 11 de janeiro de 2008).
}

lação aos gastos, muitas vezes os paradigmas da eficiência econômica e da maximização dos lucros no curto prazo são sobrepostos aos retornos sociais gerados no médio e longo prazo a partir da referida ação estatal.

Dessa forma, o conjunto de instrumentos de políticas públicas articuladas representa um ponto forte do "Projeto Educação e Inclusão", sobretudo no período de saída da beneficiária e na consolidação de Arranjos Produtivos Locais favorecendo um cenário favorável para dinamizar as relações econômicas no nível local.

\section{Observações Finais}

O trabalho procurou analisar e refletir sobre o exercício de compras públicas em favor da gestão do Desenvolvimento local. Assim, foi realizada uma descrição minuciosa do "Projeto Educação e Inclusão", de modo a perceber a articulação entre os instrumentos de organização da oferta dos uniformes escolares com os instrumentos que permitiram fazer do Estado indutor da demanda. $\mathrm{O}$ recorte temático analisou a experiência sob a teoria das compras públicas.

Tratando especificamente dos resultados percebidos a partir da análise do "Projeto Educação e Inclusão", a diminuição das despesas das famílias que têm filhos matriculados na rede pública municipal de ensino representa um resultado positivo do projeto. Além disso, a distribuição gratuita dos trajes escolares representa um ponto central para garantir a isonomia e a melhoria na oferta de serviços públicos de educação. Percebe-se ainda o caráter redistributivo do projeto, uma vez que a referida ação estatal aloca recursos públicos em setores estratégicos, neste caso, o grupo são pessoas cadastradas em programas de transferência de renda condicionadas (PTC's) visando à erradicação da pobreza extrema. Assim, desde o primeiro momento, as beneficiárias que antes estavam desempregadas, passam a receber um valor financeiro para impulsionar sua saída das condições de vulnerabilidade social. Ainda, as beneficiárias tendem a consumir em seu próprio município, contribuindo para um ciclo virtuoso da economia local (JACOBS, 1974). A criação dos 9 Arranjos Produtivos Locais no setor têxtil e confecção é, nesse sentido, um resultado proeminente de como o 
investimento na demanda efetiva do Estado, inclusive organizando a oferta local, colaborou para efeitos multiplicadores da economia local (DAVIS, 1987). Diante do cenário de vulnerabilidade social e de precarização do trabalho pré-estabelecido, a "porta de saída" apresentada nesse projeto corresponde à capacitação socioprofissional bem como à intermediação da mão de obra das beneficiárias.

Os marcos legais implementados deram maior flexibilidade e preferência aos pequenos empreendimentos coletivos nos processos licitatórios. O apoio instrumental, seja por capacitação profissional, seja por auxílio na formação de cooperativas, é proeminente nesse sentido, representando elementos fortes para a otimização dos resultados alcançados.

Em suma, o conjunto dessas medidas demonstra a possibilidade em substituir importações no âmbito local, aponta o potencial do setor da educação como indutor de processos geradores de trabalho e renda por meio da compra de uniforme e alimentação escolar, móveis, reparos e reformas nas unidades escolares. Vontade política, arcabouço jurídico consolidado e recursos próprios suficientes à demanda governamental são os elementos principais para a continuidade de um projeto que utilize o exercício de compras públicas. Nesse aspecto, o potencial de difusão dessa prática é grande. Por fim, ressalta-se a importância do envolvimento dos atores com um projeto dessa natureza, de modo a garantir maior pluralidade na oferta de bens estratégicos e, consequentemente, maiores ganhos no âmbito do desenvolvimento local.

\section{Referências}

BIDERMAN, R., L. Betiol, L. Macedo, M. Monzoni, R. Mazon (Org.). ICLEI Guia de compras públicas sustentáveis. Uso do poder de compra do governo para a promoção do desenvolvimento sustentável. 2. ed. Rio de Janeiro: Editora FGV, 2008.

BRASIL. Constituição da República Federativa do Brasil. Brasília, DF: Senado Federal, 1988.

Lei n. 8.666, de 21 de junho de 1993. Regulamenta o artigo 37, inciso XXI, da Constituição Federal, institui normas para licitações e contratos da Administração Pública, e dá outras providências. Diário Oficial da República Federativa do Brasil, Brasília, 22 de junho de 1993.

Lei Complementar n. 123, de 14 de dezembro de 2006. Institui o Estatuto Nacional da Microempresa e da Empresa de Pequeno Porte, e dá outras providências. Diário Oficial da República Federativa do Brasil, Brasília, 15 de dezembro de 2006.
MINISTÉRIO DO DESENVOLVIMENTO SOCIAL E COMBATE À FOME. Observatório de Boas práticas na Gestão do Programa Bolsa Família. Disponível em:<http://www.mds.gov.br>. Acesso em: 25 maio 2011.

CATANNI, A. D.; FERRARINI, A. V. Participação, desenvolvimento local e política pública: estratégias articuladas para a superação da pobreza. Revista Katái, v. 13, Florianópolis, 2010.

DOWBOR, Ladislau. O que é poder local. São Paulo: Editora Brasiliense, 199. Disponível em: <http:/ / dowbor. org/08podlocal.doc>.

MORAIS, José M. Crédito bancário no Brasil: participação das pequenas empresas e condições de acesso. Brasília: CEPAL, 2005. Disponível em: <http://www.eclac.cl/ publicaciones/xml/2/23902/LCL2422-P.pdf>.

DAVIS, H. Craig. Buy local programs: import substitution at the regional Level. UBC Planning Paper. Canadian Planning Issues, 25. School of Community and Regional Planning. The University of British Columbia, 1987.

GOMES, V.P. G.; ALVES, M. O Programa Oportunidade Solidária e a emancipação: uma visão crítica. In: ENCONTRO INTERNACIONAL DE ECONOMIA SOLIDÁRIA. 4., São Paulo, 2005. Anais... São Paulo: USP, 2005.

INSTITUTO BRASILEIRO DE GEOGRAFIA E ESTATÍSTICA. Rio de Janeiro: IBGE, 2010. Disponível em: <http://www.ibge.gov.br/cidadesat/topwindow. htm?1>. Acessao em: 15 abr. 2011.

JACOBS, Jane. La economía de las ciudades. 2. ed. Barcelona: Península, 1974.

KEYNES, J. M. A teoria geral do juro, do emprego e da moeda. São Paulo: Atlas, 1982.

KUGELMAS, Eduardo; SOLA, Lourdes. Recentralização/ Descentralização: dinâmica do regime federativo no Brasil dos anos 90. Tempo Social, v. 11, n. 2, p. 63-81, 1999.

LIMA, J. F.; PITAGUARI, S. O. As idéias keynesianas e o crescimento do produto nas economias locais. Interações, Campo Grande, v. 6, n. 10, p. 11-20, mar. 2005.

LINDBLOM, C. Todavia tratando de salir del paso. In: SARAVIA, E.; FERRAREZI, E. (Org.). Políticas Públicas. Brasília: ENAP, 2006. v. 1.

LOWI, Theodore J. American business, public policy, case-studies and political theory. World Politics, v. XVI, 1964.

MARTINS, R. D. A.; CALDAS, E. L. Visões do desenvolvimento local: uma análise comparada de experiências brasileiras. Interações, Campo Grande, v. 10, n. 2, p. 207-218, 2009.

MORAIS, J. M. Crédito bancário no Brasil: participação das pequenas empresas e condições de acesso. CEPAL, 2005. Disponível em: <http://www.eclac.cl/publicaciones/ xml/2/23902/LCL2422-P.pdf>.

MOREIRA, H. C.; MORAIS, J. M. Compras governamentais: políticas e procedimentos na Organização Mundial de Comércio, União Européia, NAFTA, Estados Unidos e Brasil. CEPAL, 2003.

SEBRAE. Cartilha do comprador: compras públicas alavancando o desenvolvimento. Brasília, DF: CNM, SEBRAE, 2010. 
SPINK, P. K. O pesquisador conversador no cotidiano. Psicologia Social. [online]. v. 20, p. 70-77, 2008 . Disponível em: <http://www.scielo.br/scielo.php?script=sci_ arttext\&pid=S010271822008000400010\& lng= en\&nrm=iso>.
VAZ, J. C.; CALDAS, E. L. Desenvolvimento local e políticas territoriais. In: ENCONTRO NACIONAL DE ADMINISTRAÇÃO PÚBLICA E GOVERNANÇA (EnAPG), 2006, São Paulo. Anais... São Paulo, 2006.

YIN, R. K. Estudo de caso: planejamento e métodos. 3. ed. Porto Alegre: Bookman, 2005. 212 p. 